\title{
FOTOGRAFIAS AFRORRELIGIOSAS NO FACEBOOK: NOVOS SUPORTES IMAGÉTICOS, HÁBITOS TRADICIONAIS
}

\author{
RODRIGO LEISTNER
}

\begin{abstract}
Doutor em Ciências Sociais pelo Programa de Pós-Graduação em Ciências Sociais da UNISINOS, Professor Adjunto do Instituto de Ciências Humanas em Informação (ICHI), Universidade Federal de Rio Grande (FURG). E-mail: rodrigoless@yahoo.com.br ORCID: https://orcid.org/0000-0001-5341-6825
\end{abstract}

SÍLVIA MATEUS

Mestre em História pela Universidade Federal de Pelotas (UFPel). E-mail: silvia_gon@yahoo.com ORCID: https://orcid.org/0000-0001-5781-7503

\begin{abstract}
RESUMO: Este trabalho tem por objetivo fazer algumas ponderações sobre as redes sociais, a história e a memória afrorreligiosa, em que se procura compreender como se dá a utilização do Facebook pelos afrorreligiosos. Para isso é analisada as relações entre novas tecnologias e os religiosos ao longo dos anos, dando especial atenção à fotografia, bem como é feito um estudo de caso em que é analisado um vídeo (composto por várias fotografias antigas) postado em uma página do Facebook voltada para a divulgação da cultura das religiões afro-gaúchas. Uma vez que páginas das redes sociais podem funcionar como um híbrido entre álbum fotográfico e diário, procura-se apontar que o caráter efêmero das imagens e textos constantes nas redes contêm uma série de indícios das memória e da história das religiões de matriz africana.
\end{abstract}

PALAVRAS-CHAVE: História; Memória; Fotografia; Facebook; Religiões de Matriz Africana. 


\title{
AFRORELIGIOUS PHOTOGRAPHS ON FACEBOOK: NEW IMAGETIC SUPPORTS, TRADITIONAL HABITS
}

\begin{abstract}
This work aims to make some considerations about social networks, history and Afro-religious memory, in which it seeks to understand how the use of Facebook by Afro-religious people occurs. For this, the relationship between new technologies and religious people is analyzed over the years, giving special attention to photography, as well as a case study in which a video (composed of several old photographs) posted on a Facebook page is analyzed. focused on disseminating the culture of Afro-Gaucho religions. Since social media pages can function as a hybrid between photo album and diary, we try to point out that the ephemeral character of the images and texts contained in the networks contain a series of indications of the memory and history of religions of African origin.
\end{abstract}

KEYWORDS: Story; Memory; Photography; Facebook; African Matrix Religions.

Recebido em: 07/12/2020

Aprovado em: 19/01/2021

DOI: http://dx.doi.org/10.23925/2176-2767.2021v70p150-174 


\section{Introdução}

A sociedade vigente, na qual as religiões afro-brasileiras estão inseridas, tem passado ao longo das décadas por transformações tecnológicas significativas, e essas culturas religiosas não estão imunes aos reflexos dessas mudanças. Assim, procura-se neste trabalho fazer algumas ponderações sobre as redes sociais, a história e a memória' afrorreligiosa.

Em se tratando das religiões de matriz africana é preciso considerar que há uma série de variações no território brasileiro, passando pelas mais conhecidas como o Candomblé, Tambor de Mina, Batuque, até as formas mais ocidentalizadas, como a Umbanda e a Quimbanda. Para este trabalho serão analisados dados referentes as culturas afrorreligiosas gaúchas, concentradas nos terreiros localizados em Porto Alegre.

Neste estudo procura-se compreender como se dá a utilização do Facebook pelos afrorreligiosos. Para isso é analisada como se dão as relações entre novas tecnologias e os religiosos ao longo dos anos, dando especial atenção à fotografia. Também é analisada, de forma breve, a proximidade entre os capitais sociais das redes e das religiões de matriz africana.

Após tratar do processo formativo das religiões afro-brasileiras, passase a refletir sobre o papel das fotografias para essas culturas religiosas e a transição da guarda física das imagens produzidas durante as festas públicas para o meio digital e de que forma a memória se preserva nesse meio.

Por fim, faz-se um breve estudo de caso a partir de uma página do Facebook destinada a divulgação das cultura afrorreligiosa (festas públicas, entrevistas com religiosos, anúncios de produtos e serviços para este universo), Kizomba. Dentre as várias publicações foi analisado um vídeo em homenagem ao Exu Seu Sete, entidade da quimbanda que Mãe leda de Ogum recebe há quase 60 anos. O vídeo é constituído por várias fotografias pertencentes ao acervo pessoal da religiosa que, somados aos comentários, formam um híbrido entre álbum fotográfico e diário. Se num primeiro

\footnotetext{
${ }^{1}$ Aqui memória é entendida como uma reconstrução continuamente atualizada no passado. E uma vez que a transmissão da memória nas sociedades tradicionais se dá sem mediação, e nas modernas, boa parte mediatizada, a fotografia é aqui pensada como uma arte da memória, permitindo que vários elos sejam mantidos, uma vez que suportam uma narrativa entre os sujeitos consigo, com sua família, com seu grupo, indícios, suportes compartilhados, que reavivam aquela memória (CANDAU, 2018; CATROGA, 2001).
} 
momento os dados, informações e registros ali constantes tenham um caráter efêmero por conta da dinâmica da própria rede, contêm uma série de indícios das memória e da história das religiões de matriz africana, abrindo um interessante caminho investigativo.

\section{A fotografia nas religiões afro-gaúchas}

As religiões de matriz africana no Brasil são heterogêneas tendo em vista a diversidade de vertentes e denominações que compõem esse universo, resultado de adaptações ligadas não apenas aos diferentes contextos culturais e geográficos em que essas formas se desenvolveram no país, mas, ainda, às tradições africanas envolvidas (iorubás, jejes e bantas). Foi a partir desses diferentes processos de adaptação cultural que resultaram as diferentes denominações da cultura afro-brasileira, como as vertentes mais antigas e "tradicionais" como o Candomblé baiano, o Xangô pernambucano, ou ainda as denominações mais "ocidentalizadas" e surgidas no sudeste brasileiro na primeira metade do século XX, caso da Umbanda.

No Rio Grande do Sul são praticados o Batuque (formato mais africano, com cânticos em Yorubá e sacralização de animais nos ritos aos orixás), a Umbanda (culto aos caboclos, índios, pretos velhos e cosmes com cânticos em português) e a Quimbanda (culto aos exus e pombagiras, conta com imolações de animais e cânticos em português). Trata-se de um processo formativo ainda em andamento, tendo em vista que, além de cada vertente ser composta por vários formatos, as dinâmicas inerentes dessas religiosidades as fazem seguir se adaptando ou se ressignificando por conta das modificações culturais da sociedade vigente.

Consideradas tradicionais, são iniciáticas e mesmo ancorando a transmissão de conhecimento e cultura prioritariamente por via da oralidade, as religiões de matriz africana não estão apartadas das mudanças que ocorrem no mundo secular, tendo em vista que boa parte dos terreiros estão concentrados em espaços urbanos, assim, muito das memórias e da história dessas culturas podem ser encontradas em diferentes suportes (livros, fotografias, vídeos) e mídias (analógicas e digitais). 
Antropólogos, como Pierre Verger, jornalistas, como José Medeiros,2 foram alguns dos responsáveis pela divulgação junto ao público leigo de imagens fotográficas sobre as religiões de matriz africana (Candomblé), principalmente a partir da década de 1950. Paralelamente, conforme as câmeras fotográficas foram ficando acessíveis à população, os próprios religiosos que fotografavam suas festas particulares, passaram a fazer registros também das festividades públicas afrorreligiosas. Paulatinamente as fotos passaram a fazer parte dessas culturas religiosas de tal modo que começaram a circular fora dos muros dos terreiros. Tanto que, no Rio Grande do Sul, a partir da década de 1990, jornais endógenos (produzidos por e para afrorreligiosos) passaram a divulgar não somente anúncios de serviços espirituais, como também convites para festas afrorreligiosas e, posteriormente, fotografias desses mesmos eventos.

Mas, conforme as mídias foram sendo atualizadas e as câmeras analógicas deram lugar às digitais e, as caixas e sacolas plásticas onde eram guardadas as fotos foram substituídas pelas nuvens na internet, a circulação também sofreu mudanças. Jornais impressos endógenos migraram ao longo dos anos 2000 para as redes sociais, como o Facebook, possibilitando, inclusive, que a quantidade de fotografias que podem ser visualizadas seja superior ao que permitia os periódicos impressos.

Pode se tratar de um processo que os religiosos mais antigos ou ortodoxos não concordem por conta de quem possa estar do outro lado da tela vendo as imagens produzidas pelos próprios afrorreligiosos, por exemplo,

\footnotetext{
2 Os trabalhos de Verger chamaram a atenção da imprensa para os orixás no Brasil, tanto que na década de 1950 as fotografias utilizadas nas reportagens das revistas Paris Match e O Cruzeiro fizeram a comunidade religiosa tradicional baiana se reunir e discutir sobre a permissão para fotografar ou não os ritos iniciáticos. Conforme Ramos (2009, p. 14), "As polêmicas surgiram em torno das fotografias sobre o rito iniciático mais conhecido como 'feitura de santo', publicadas em 1951 na revista francesa Paris Match e na brasileira O Cruzeiro. A reportagem da Paris Match foi publicada em 12 de maio de 1951 com o título 'As possuídas da Bahia'. O texto anunciava o lançamento do livro O Cavalo dos Deuses, do cineasta Henri-Georges Clouzot, que veio ao Brasil com a pretensão de fazer um filme sobre o país e durante uma passagem pela Bahia escolheu - Candomblé como tema de uma série fotográfica. O texto e as fotografias da Paris Match, que mostram detalhes de um processo de iniciação comandado por um sacerdote chamado no texto de Nestor, um nome fictício, receberam severas críticas de intelectuais como Alberto Cavalcanti e Roger Bastide, mas não intimidaram a revista $\bigcirc$ Cruzeiro a dar a resposta em 15 de setembro de 1951 com uma reportagem semelhante assinada por Arlindo Silva e com fotografias feitas por José Medeiros, intitulada 'As noivas dos deuses sanguinários'. As fotos do passo-a-passo do rito de iniciação, como a epilação (raspagem dos cabelos) e as iaôs, nome que se dá a quem passa pelo ritual sendo banhadas com o sangue de animais, provocaram até a convocação, via jornais, de uma reunião da Federação Bahiana do Culto AfroBrasileiro (Febacab) para discutir as duas reportagens".
} 
imolações - o que pode impactar ou chocar um pessoa leiga -, mas é uma dinâmica que ocorre em consonância com o que ocorre no dia a dia da sociedade vigente. As novas gerações de afrorreligiosos socializam, trocam informações e acusações via redes sociais, despertando a curiosidade e participação dos mais velhos e menos afeitos aos novos formatos comunicacionais. As religiões de matriz africana seguem sendo tradicionais em seus ritos e preceitos, mas seus partícipes estão tão imersos nas novas tecnologias quanto qualquer leigo e levam para esse novo espaço de sociabilidades seus conhecimentos, dúvidas e fé.

Mesmo que haja restrições quanto à registros fotográficos em alguns terreiros, eles ocorrem há décadas, indicando que vem acontecendo uma paulatina simbiose entre a tradição (oralidade) e a modernidade (registros através de variadas mídias como a escrita, fotográfica e sonora).

\begin{abstract}
Se, por um lado a modernidade acelerou os tempos e reduziu as distâncias gerando uma padronização que cada vez mais se universaliza, por outro a popularização da tecnologia gerou uma democratização de novas linguagens que foram introduzidas em muitas camadas da sociedade. Nas grandes cidades, a partir dos anos 30, a memória, tanto a individual quanto familiar, passou a ser construída tendo como base o suporte imagético. A fotografia veio contar às futuras gerações, ou mesmo àqueles que não presenciaram momentos importantes, cenas que merecem serem lembradas (PREVITALLI, 2007, p. 70).
\end{abstract}

Todavia, a permissão ou o uso do registro fotográfico não é um consenso nas religiões de matriz africana, seja entre as variantes mais africanizadas, como Candomblé, Batuque, Xangô; seja entre as diferentes vertentes mais ocidentalizadas como Umbanda e Quimbanda. A Umbanda é a vertente das religiões afro-brasileiras que melhor relação tem com o registro fotográfico, uma vez que os rituais e cerimônias não contemplam segredos, ou seja, interdições ocorrem por uma opção pessoal do cacique . Contudo, entre as demais formas religiosas afro-brasileiras há variações entre o que pode ou não ser registrado.

O que está por trás das restrições à fotografia não é, fundamentalmente, um tabu generalizado em relação à imagem fotográfica em si, mas a lei do segredo, que regula a transmissão e circulação do conhecimento do sagrado em todas as modalidades inclusive quando as informações são passadas oralmente. [...] Somente

\footnotetext{
${ }_{3}^{3}$ Religioso da Umbanda cuja entidade já atingiu uma graduação em que pode ter seu próprio
} terreiro. 
as partes públicas da cerimônia podem ser fotografadas. Fotografias de rituais privados, como iniciação e sacrifício, não são permitidas (CASTILLO, 2013, pp. 50-60, 62).

No Rio Grande do Sul, mais no Batuque, e menos na Quimbanda, a sacralização é um momento que não pode ser registrado, pois ali residem vários segredos que constituem estas formas religiosas. Há objetos que simbolizam o orixá ou as entidades, e esse conjunto (chamado pelos religiosos de obrigação) que, também recebe o sangue da imolação, conforme a tradição, não poderia ser fotografado.

Este tipo de interdição, com relação aos rituais de iniciação e outros que envolvam imolação também ocorrem no Candomblé. Mas o Batuque possui um tabu que não é encontrado em nenhuma outra vertente, que é o segredo com relação à "ocupação" do médium pelo orixá. Se a fotografia do transe não agrada aos candomblecistas mais ortodoxos, para outros não há motivos para proibir o registro. Já no Batuque, o fato de que o orixá "chegou" no mundo não deve ser jamais revelado ao "cavalo de santo", pois conforme reza a tradição, a pessoa pode enlouquecer, morrer ou o orixá pode não "vir" mais, assim, esse tipo de registro, até então, não veio às público.

As festas das religiões afro-brasileiras são os momentos em que as sociabilidades dessas culturas estão em seu ápice, pois congregam não somente os partícipes, mas chamam também a sociedade na qual estão inseridas a conhecer, participar, festejar os orixás ou entidades. As mediações, comunicações e trocas ocorrem em todas as direções, do sagrado entre si, do sagrado com o profano, do profano com o profano. Ali, naquele espaço privado e cheio de segredos, agora aberto para a congregação, as identidades são fortalecidas e atualizadas. Pensadas com semanas de antecedência, as festas afrorreligiosas são destinadas não somente a homenagear, mas, principalmente, para agradecer, pois está sendo finalizado algum ritual, e ele deve se dar de forma farta, farta de alimentos, farta de dança e canto, farta de pessoas, farta de alegria, farta de axé. Mas o significado dessas comemorações vai além, pois, conforme Fonseca (1997), possuem três funções: religiosa, proselitista e de aprendizagem.

Fotografar a festa permite que famílias-de-santo e as irmandades umbandistas possam relatar visualmente a história de seu terreiro e de sua ancestralidade, pois é comum haver imagens de Babalorixás/Yalorixás ou 
Caciques com seus filhos de santo ou com seus padrinhos e zeladores nas paredes do salão. Assim, para além do registro de um momento, a fotografia legitima representações e "serve também como um meio importante para a construção da identidade, tanto individual quanto coletiva" (CANABARRO, 2015, pp. 31-32).

As fotografias das festas auxiliam no processo de rememoração por parte dos afrorreligiosos, o que contribui na constituição e reforço da identidade coletiva, permitindo a reorganização simbólica quando novos códigos passam a se apresentar nessa cultura religiosa, ou seja, "funcionam como mediadoras da comunicação, dos hábitos culturais e da vida social" (BELEZA, 2019, p. 3), documentando as sociabilidades das religiões de matriz africana.

\section{O uso das redes sociais pelos afrorreligiosos: novas tecnologias, antigas "manias"}

As religiões de matriz africana são caracterizadas como tradicionais uma vez que são iniciáticas e a transmissão dos ensinamentos se dá, prioritariamente, via oralidade. Mas não se pode pensar que se tratam de culturas religiosas estagnadas no tempo, pois todas as tecnologias disponíveis na sociedade envolvente podem estar presentes nos terreiros de alguma forma. Um exemplo dessa dinâmica afrorreligiosa é o uso da fotografia para fazer registros das festas públicas, um procedimento que nem todos os religiosos concordam, mas que tem sido feito desde os tempos das primeiras máquinas Kodak, passando pelas câmeras digitais e hoje, vídeos também têm sido feitos concomitantemente com as fotos através dos smartphones, sejam dos próprios partícipes, de visitantes ou dos profissionais contratados para fazer as imagens a serem eternizadas. É possível, inclusive, assistir a festas das religiões de matriz africana ao vivo através de transmissões feitas em páginas do Facebook.

Rendeiro (2012, p. 4) aponta que as redes sociais são "um fenômeno da comunicação, configurando uma parte relevante desse ciberespaço, indicativo de uma cultura e de uma prática já incorporada ao cotidiano", sendo que muitos afrorreligiosos têm páginas pessoais ou de seus terreiros, as utilizando para comunicar-se tanto com seus filhos-de-santo (postando 
mensagens sobre histórias dos orixás e práticas rituais), quanto com clientes (anunciando contatos para marcar jogos de búzios) ou outros religiosos (postando convites para festas públicas). As redes sociais não só se tornaram uma extensão da forma de se comunicar da cultura afrorreligiosa, mas também tornaram públicas certos comportamentos que antes ficavam restritos aos próprios terreiros.

O ser visto é uma das prerrogativas dessas culturas aquele religioso "vive da religião", e o anúncio é uma maneira de atrair clientes. No Rio Grande do Sul, em meados dos anos 1980 era possível encontrar nas páginas das listas telefônicas anúncios pagos por Babalorixás/Yalorixás com o endereço e telefone do terreiro. Já no decorrer dos anos de 1990 jornais endógenos (feitos por e para religiosos) ${ }^{4}$ passaram a ser o melhor local para se colocar "à vista" da comunidade, uma vez que esses impressos eram vendidos em locais como - Mercado Público de Porto Alegre (bem como em outros espaços ou distribuídos nas festas). Por outro lado, nesses jornais também era possível ver fotografias de festas públicas de religiosos que pagavam por esse espaço.

Tanto no Batuque as festas públicas destinadas aos Orixás, bem como as giras ou curimbas de Exús e Pomba-Giras, os templos ficam movimentados, tanto por conta da decoração, quanto pela preparação das comidas esteticamente tudo deve estar impecável. No Batuque, além das oferendas servidas somente para os Orixás, são oferecidas aos visitantes ao longo da cerimônia as comidas tradicionais (amalá, canjica, assados dos animais que foram imolados, etc.) e comuns (doces e salgados variados), bem como bebidas quentes e frias não alcoólicas. Excetuando as especificidades (que não serão tratadas aqui pela proposta deste trabalho), na Quimbanda a única

\footnotetext{
${ }^{4}$ Ao longo dos anos 1990 surgiram vários jornais impressos produzidos por afrorreligiosos para esta mesma comunidade. Um nicho ainda inexplorado, eram verdadeiras vitrines de anúncios, desde catálogo de religiosos com seus respectivos endereços e telefones, prestadores de serviços (aviários e floras), mas também como um espaço privilegiado para que os donos de terreiros apresentassem a toda a comunidade sua casa religiosa, seus filhos-de-santo, seus amigos e convidados, se ver e ser visto. Os jornais impressos voltados especificamente para as comunidades de terreiro começaram a ser vendidos no final dos anos de 1980. O primeiro jornal foi Baba de Orixá (1988) fundado por Lindomar Alves (que o vendeu para o JOCAB); entre os anos de 1989-1992 Enildo Paulo Pereira (Paulão) fundou o Jornal dos Cultos Afro-brasileiros - JOCAB (fora de circulação); no início dos anos de 1990 surgiu o Tribuna Africanista e o Estrela do Oriente (ambos fora de circulação); no ano de 1996 Verá de Oxalá funda o (ainda em circulação somente impressa). Nos anos 2002 Alberto Flores funda o Bom Axé, que no ano de 2008 passa a se chamar Grande Axé. Via de regra, os fotógrafos contratados pelos jornais são partícipes das religiões de matriz africana, alguns são fixos, outros temporários, sendo que muitos são profissionais. As fotografias são cobradas por festa (independentemente do tempo ou quantidade de imagens feitas).
} 
diferença "alimentar" é o consumo de bebidas com álcool, tanto por parte das entidades, quanto dos convidados. Os visitantes iniciados nos cultos costumam usar suas melhores indumentárias para estas ocasiões.

Portanto, as festividades constituem-se no principal espaço onde as sociabilidades poderão ser atualizadas. Tão importante quanto celebrar divindades, esses eventos são sempre realizados para que os códigos de um terreiro sejam visualizados por outros, por isso tamanha preocupação com a organização, limpeza, decoração, originalidade, fartura de alimentos e bebidas, que nada significariam sem a presença de convidados (religiosos e ilustres), amigos, clientes e vizinhos.

Estes momentos festivos eram (e ainda são) pensados não somente para enaltecer os orixás, mas também marcar presença na comunidade afrorreligiosa, sendo organizados com muitos meses de antecedência, os donos dos terreiros sabiam que receberiam convidados mais dispostos a procurar defeitos do que participar da festa:

A festa é o momento que o templo se expõe ao público, sobretudo ocasiões privilegiadas de encontro da comunidade, onde seus membros vêem e são vistos. [...]. Os chefes, particularmente, sabem muito bem avaliar o que está subjacente às exterioridades [...] Por isto, a grande preocupação do anfitrião é que seu grupo atue de forma impecável, em todos os sentidos, todo o brilho é pouco, mesmo porque sua intensidade, pode, também, disfarçar aspectos que não interessa serem percebidos, mas que costumam ser objetos da catação: muitos integrantes do grupo maior comparecem às festas alheias com o objetivo precípuo de catar, isto é, tentar identificar aspectos, mesmo ínfimos, que supostamente possam constituir-se em desvios rituais, para serem transformados em motivos de crítica e deboche, que depois correrão de boca em boca, pela comunidade (CORRÊA, 1998, pp. 103104).

Os jornais endógenos impressos permitiram que mais religiosos pudessem "dar uma olhadinha" em eventos que não puderam estar presentes, não sendo incomum que ocorressem comentários de todos os tipos junto à família religiosa sobre as festas alheias.

Por meio das fotos, temos também uma relação de consumidores com os eventos, tanto com os eventos que fazem parte de nossa experiência como com aqueles que dela não fazem parte — uma distinção de tipos de experiência que tal consumo de efeito viciante vem turvar. Uma terceira forma de aquisição é que, mediante máquinas que criam imagens e duplicam imagens, podemos adquirir algo como informação (e não como experiência). De fato, a importância das imagens fotográficas como o meio pelo qual cada vez mais eventos 
entram em nossa experiência é, por fim, apenas um resultado de sua eficiência para fornecer conhecimento dissociado da experiência e dela independente" (SONTAG, 2004, p. 87).

Sontag (ibidem, p. 52) também aponta que o ato de fotografar é um rito social e um instrumento de poder, permitindo que anfitriões orgulhosos de sua casa possam perfeitamente mostrar fotos do lugar onde moram para deixar claro aos visitantes como se trata de uma casa, de fato, maravilhosa. E, uma vez que o poder está em cena, não há espaço para a simplicidade, pois para distinguir-se das demais representações sociais é preciso que haja grandeza ou ostentação, decoração ou fausto, cerimonial ou protocolo. Elas permitem consumir os eventos (tanto os que fazem e os que não fazem parte da vida do sujeito). Fatos e coisas fotografadas podem se destinar a outros usos além do belo e do feio, do verdadeiro e do falso, pois o que pode estar em jogo é algo bem distinto: "o interessante" (SONTAG, 2004, p. 96).

Com o advento da internet e adesão dos afrorreligiosos às redes sociais, essas sociabilidades passaram a ocorrer também em páginas como as do Facebook. Todavia, os comentários sobre as festas públicas (se a tradição estava ou não sendo seguida, a fartura ou falta desta, a luxuosidade ou simplicidade das vestimentas e decoração, etc.) passaram a constar nos comentários das publicações postadas. Como aponta Rendeiro (2011, p. 261),

\begin{abstract}
"As comunidades virtuais seriam assim não apenas lugares de encontro, mas também um meio para se atingir determinados fins" (COSTA, 2008, p. 244). O que se ressalta no terreno das comunidades e do capital social é a percepção do outro; de uma capacidade de interação desenvolvida pelo indivíduo; de sua capacidade para estimular confiança; reconhecendo nesse processo "comportamentos, intenções e valores que compõem o seu meio" (Ibidem). O capital social ficaria assim entendido como "a capacidade de interação dos indivíduos, seu potencial para interagir com os que estão a sua volta, com seus parentes, amigos, colegas de trabalho, mas também com os que estão distantes e que podem ser acessados remotamente" (Ibidem, p. 240). Por essa premissa, capital social significaria "a capacidade de os indivíduos produzirem suas próprias redes, suas comunidades pessoais". Também pode ser entendido como "normas e valores que governam as interações entre as pessoas e as instituições com as quais elas estão envolvidas" (Ibidem, p. 239).
\end{abstract}

Recuero (2009) elenca os seguintes capitais sociais encontrados nas redes da internet: visibilidade, reputação, popularidade, autoridade (poder de influência de um nó na rede social). A autora também aponta que os "processos dinâmicos das redes são consequência direta dos processos de 
interação entre os atores. Redes são sistemas dinâmicos e, como tais, sujeitos a processos de ordem, caos, agregação, desagregação e ruptura" (ibidem, p. 80), e entre esses elementos dinâmicos destaca "o aparecimento da cooperação da competição e do conflito como processos sociais que influenciam a rede [...] estudo das regularidades e irregularidades nas interações, que gera um padrão na relação social" (ibidem, p. 81).

Todos estes elementos supracitados, conforme antropólogos ${ }^{5}$ que se dedicam ao estudo das religiões afro-gaúchas, também estão presentes nas religiões de matriz africana. Cabe lembrar que os terreiros não estão sob o comando de uma autoridade central que organize e dê diretrizes de atuação, mas mesmo sendo autônomos entre si, não é impeditivo para a existência de uma rede de relações sociais de considerável amplitude (iniciados, família, amigos, vizinhos, simpatizantes, clientes, filhos com terreiros abertos) social, geográfica e econômica. Mesmo independentes entre si,

todos os sacerdotes comungam de um mesmo patrimônio simbólico, sistemas de crenças, práticas rituais e visão do mundo, e sobretudo se reconhecem uns aos outros, em que pesem as restrições, como participantes legítimos da comunidade (CORRÊA, 1998, pp. 75-76),

não sendo incomum visitas entre si nas festas religiosas. Assim, as condutas, os modos, as relações que ocorrem nas redes sociais não são de todo estranhas para os afrorreligiosos, de modo que não estão sendo gerados novos hábitos por conta das mudanças tecnológicas, apenas houve uma atualização nas formas de comunicação.

\section{Diversidade afrorreligiosa nas páginas do facebook}

A diáspora africana espalhou por boa parte das Américas milhões e milhões de negros escravizados entre os séculos XVI e XIX. Capturados em qualquer região, eram reunidos nos portos africanos junto com pessoas de diferentes povos. Comprados para trabalhar sob regime forçado nos campos ou nas cidades, eram distribuídos nos mercados de cidades litorâneas, principalmente das Antilhas, Guianas, Venezuela, Brasil e América do Norte. Contudo, mesmo que os laços sociais tenham sido dissolvidos à força, suas

\footnotetext{
${ }^{5}$ Para mais informações sobre o tema: Norton Corrêa; Rodrigo Leistner.
} 
culturas atravessaram o Atlântico junto com suas memórias, as quais foram essenciais para enfrentar a nova situação nas Américas, sendo as religiosidades exemplos pertinentes.

Mesmo constituídas por sujeitos oriundos de diferentes culturas, as religiões africanas possuíam algumas características que os aproximavam. Com a diáspora não havia mais um sistema organizado do qual as pessoas escravizadas fizessem parte, foi preciso acionar o passado através das memórias e elaborar dentro de um novo contexto outras modalidades de transmissão de suas culturas, passando pela continuidade e invenção. A cultura religiosa afro-brasileira preencheu os "vazios" deixados pela escravidão através de substituições e resistências, pois a "esquecida memória não é sempre um campo de ruínas, pode ser uma construção" (CANDAU, 2005, pp. 117-118). Desse processo resultou a paulatina organização das religiões afroamericanas, sendo um dos principais expoentes as religiões de matriz africana no Brasil. Segundo Prandi (1996, pp. 65-66), as religiões negras

\begin{abstract}
Formaram-se em diferentes áreas do Brasil, com diferentes ritos e nomes locais derivados de tradições africanas diversas: candomblé na Bahia, xangô em Pernambuco e Alagoas, tambor de mina no Maranhão e Pará, batuque no Rio Grande do Sul, macumba no Rio de Janeiro. [...] Além do queto, as seguintes 'nações' também são do tronco iorubá (ou nagô, como os povos iorubanos são também denominados): efã e ijexá na Bahia, nagô ou eba em Pernambuco, oió-ijexá ou batuque de nação no Rio Grande do Sul, mina-nagô no Maranhão, e a quase extinta 'nação' xambá de Alagoas e Pernambuco.
\end{abstract}

Processos de hibridismo e justaposição seguiram ocorrendo nas religiões de matriz africana, ao passo que mesmo os cultos mais tradicionais acabaram por adaptar-se de algum modo às modificações culturais da sociedade vigente e, conforme a sociedade foi-se modificando, uma série de adaptações, formatações, ressignificações seguiram ocorrendo, resultando em processos formativos ainda em andamento, ou seja, não encerrados, pois estão diretamente ligados às dinâmicas inerentes dessas religiosidades.

Essa dinâmica e diversidade das religiões afro-brasileiras também estão presentes nas páginas do Facebook, não somente porque religiosos de diferentes formatos e vertentes (tanto de várias partes do Brasil quanto de fora) estão ali inscritos, mas também porque se fazem representar nos perfis conforme um determinado objetivo. A maioria dos Babalorixás/Yalorixás 
criam somente perfis pessoais ${ }^{6}$, outros também fazem do terreiro; há os prestadores de serviços especializados para o segmento afrorreligioso, tal como fotógrafos, tamboreiros (alabês), costureiras, produtoras, jornais endógenos, etc. ${ }^{7}$ Trata-se de um conjunto de informações (imagéticas, sonoras ou textuais, quando não todos estes em um mesmo post) referentes a estas culturas religiosas que alimentam diariamente essa rede social. Contudo, um olhar um pouco mais atento permite notar que ali estão sendo deixados uma série de vestígios relativos à história e a memória das religiões de matriz africana.

\section{Memória afrorreligiosa on-line}

Uma vez que uma fotografia é inserida em uma página do Facebook, automaticamente é criado um álbum digital para aquele perfil, ao que Musse (2019, p. 85) chama de "álbum afetivo, como preferimos chamá-lo, uma vez que os sujeitos representados nos álbuns atuais não necessariamente fazem parte da família de quem tem o álbum, mas, sim, são sujeitos com quem este se relaciona afetivamente, nessa nova relação de familiaridade". Esse tipo de relacionamento "afetivo" faz parte das sociabilidades dos afrorreligiosos, tendo em vista que em muitas das fotografias analógicas feitas nas festas públicas as visitas e a família religiosa eram o mote. Esse aspecto possibilita que a transição entre os álbuns físicos para os digitais transcorra de uma maneira menos impactante quando comparado ao processo por que têm passado os álbuns de família.

Musse (2019, p. 80) aponta para uma função pouco perceptível para o usuário que compartilha a fotografia de um momento importante,

A fotografia hoje passa a ter uma conotação muito similar da que tinha o texto para o diário íntimo. Ela passa a representar o registro pessoal que fazemos do cotidiano, a narrativa de nossos pequenos e grandes momentos, porém, não queremos que fique guardada a sete chaves e, sim, que seja vista pelo máximo possível de pessoas a fim de narrar seu cotidiano.

\footnotetext{
${ }^{6}$ Por pessoais entenda-se que utilizam seus nomes religiosos, os quais são de conhecimento público. Quanto à criação de perfis, muitos dos religiosos que não se adaptam as novas tecnologias têm páginas criadas e/ou mantidas por terceiros.

7 Há outras categorias, como os grupos e outras que ainda não foram identificadas que não serão aqui analisadas tendo em vista não ser a proposta deste trabalho.
} 
Já o álbum digital, ainda segundo Musse (2019, p. 82) "ele continua, mesmo que não seja sua finalidade principal, servindo para armazenar e arquivar fotografias".

Quando algo é fotografado, torna-se parte de um sistema de informação, adapta-se a esquemas de classificação e de armazenagem que abrangem desde a ordem cruamente cronológica de sequências de instantâneos colados em álbuns de família até o acúmulo obstinado e o arquivamento meticuloso necessários para usar a fotografia na previsão do tempo, na astronomia, na microbiologia, na geologia, na polícia, na formação médica e nos diagnósticos, no reconhecimento militar e na história da arte. As fotos fazem mais do que redefinir a natureza da experiência comum (gente, coisas, fatos, tudo o que vemos - embora de forma diferente e, não raro, desatenta - com a visão natural) e acrescentar uma vasta quantidade de materiais que nunca chegamos a ver. A realidade como tal é redefinida - como uma peça para exposição, como um registro para ser examinado, como um alvo para ser vigiado. A exploração e a duplicação fotográficas do mundo fragmentam continuidades e distribuem os pedaços em um dossiê interminável, propiciando dessa forma possibilidades de controle que não poderiam sequer ser sonhadas sob o anterior sistema de registro de informações: a escrita (SONTAG, 2004, pp. 87-88).

Alguns pesquisadores apontam para a o caráter perecível das imagens postadas nessas páginas, perenidade resultante das demandas de consumo exacerbadas pela internet. Todavia, "Segundo Marion Strecker (2012), ele [facebook] está se tornando uma espécie de 'Catálogo da Terra Inteira' com as histórias e fotos que as pessoas vão voluntariamente alimentando na rede social. Este catálogo aglutinaria as experiências das pessoas, suas memórias e suas narrativas sobre o mundo" (HENRIQUES, 2013, p. 269). Mais do que um caráter de efemeridade, a conforma uma nova memória, "a memória do presente. Essa memória é aquela do imediatismo, dos acontecimentos vividos e narrados ao mesmo tempo" (VIRILIO apud HENRIQUES, 2013, pp. 260-261).

Cunha (2011) aponta para uma constante atualização da memória propiciada pelas redes sociais, uma vez que registros visuais do passado ali "postados" tornam a se apresentar ao usuário, seja pela lembrança trazida à tona pelos algoritmos da rede ou das pessoas com quem aquele momento foi compartilhado. "Somados, redes sociais, com imagens, registros, narrativas, que falam de pessoas e lugares, conectados à digitalização permanente de documentos, o mundo vive um tempo em que a memória organizada em rede constitui uma grande e larga memória" (ibidem, p. 105). 
Redes sociais como o Facebook são grandes arquivos com uma série de informações das, e sobre as pessoas (suas memórias e percepções), espaço de narrativas, de memórias e de história de anônimos ou "famosos", de diferentes grupos, gêneros, culturas, tal como as afrorreligiosas. Na próxima sessão serão analisadas imagens e alguns comentários de uma postagem constantes em uma página do Facebook focada na comunidade afrorreligiosa gaúcha.

\section{Kizomba, um breve estudo de caso}

Foi mencionado anteriormente que na década de 1990 surgiram no Rio Grande do Sul jornais impressos voltados para assuntos referentes às religiões de matriz africana gaúcha. Nos anos 2000 paulatinamente esses periódicos foram perdendo espaço, tendo em vista que muitos religiosos migraram para a internet (blogs, sites, redes sociais), sendo que alguns desapareceram e outros, como o Grande Axé, no final da década passaram a se adaptar às demandas de seu público. Ao longo dos anos 2010 outros jornalistas, fotógrafos, produtoras, alabês, costureiras, passaram a usar as redes não somente para ofertar serviços para os afrorreligiosos, mas também postar fotos antigas, contar antigas histórias de religiosos, entidades ou orixás que há muito circulavam na comunidade e, fazer entrevistas com donos de terreiros.

O acompanhamento por um tempo prolongado da página Grande Axé, a fim de observar as fotografias afrorreligiosas para pesquisa, fez com que o algoritmo do Facebook mostrasse outras com o mesmo foco. Assim, em um processo contínuo, páginas foram levando a outras. Mas, o mapeamento das entrevistas não resultou dessa metodologia, mas sim através da pesquisa no próprio Facebook utilizando palavras-chaves (como entrevista ou o nome de um religioso conhecido na comunidade), resultando na localização de 16 páginas naquela rede social (Tabela 1) que, desde 2008, registraram relatos de 122 Babalorixás e Yalorixás, sendo que alguns participaram de mais de 1 programa (Tabela 2). 
TABELA 1 - Páginas do Facebook com entrevistas de Afrorreligiosos

\begin{tabular}{|l|c|c|c|c|c|c|c|}
\hline \multicolumn{1}{|c|}{ PÁGINA } & $\mathbf{2 0 0}$ & $\mathbf{2 0 1}$ & $\mathbf{2 0 1}$ & $\mathbf{2 0 1}$ & $\mathbf{2 0 1}$ & $\mathbf{2 0 2}$ & Tota \\
& $\mathbf{8}$ & $\mathbf{6}$ & $\mathbf{7}$ & $\mathbf{8}$ & $\mathbf{9}$ & $\mathbf{0}$ & $\mathbf{I}$ \\
\hline A Hora do Axé & 4 & - & - & - & - & - & 4 \\
\hline Amigos do Axé & - & - & 5 & 16 & - & - & 21 \\
\hline Amigos do Exú Maré & - & - & - & - & 1 & 1 & 2 \\
\hline $\begin{array}{l}\text { Batuque do Rio Grande do } \\
\text { Sul }\end{array}$ & - & - & - & - & 3 & 5 & 8 \\
\hline Batuque RS & - & - & - & - & 3 & - & 3 \\
\hline Bella África* & - & - & - & - & - & 7 & 7 \\
\hline Canal Mojubá & - & - & 1 & - & - & - & 1 \\
\hline De Frente com Pai Ruy & - & - & - & - & - & 1 & 1 \\
\hline Foco em Fé & - & - & - & 2 & - & - & 2 \\
\hline Grande Axé & - & - & - & 6 & 5 & 10 & 21 \\
\hline Kizomba & - & - & 1 & 39 & 5 & 16 & 61 \\
\hline Mãe Fernanda de Xapanã** & - & - & - & - & 3 & - & 3 \\
\hline Na Fé pelo Axé & - & - & - & - & - & 2 & 2 \\
\hline Programa África & - & - & - & - & - & 3 & 3 \\
\hline Templo a Cabana & - & 14 & 5 & - & - & - & 19 \\
\hline Total & $\mathbf{4}$ & $\mathbf{1 4}$ & $\mathbf{1 2}$ & $\mathbf{6 3}$ & $\mathbf{2 0}$ & $\mathbf{4 3}$ & $\mathbf{1 5 8}$ \\
\hline
\end{tabular}

* Loja de roupas africanas do litoral gaúcho

** A Yalorixá realizou 3 entrevistas com seu avô de santo

TABELA 2 - Afrorreligiosos entrevistados mais de uma vez

\begin{tabular}{|l|c|l|c|}
\hline \multicolumn{1}{|c|}{ RELIGIOSO } & ENTREVISTAS & \multicolumn{1}{|c|}{ RELIGIOSO } & ENTREVISTAS \\
\hline $\begin{array}{l}\text { Mãe Nara de } \\
\text { Xangô }\end{array}$ & 2 & Pai Pedro de Oxum & 2 \\
\hline $\begin{array}{l}\text { Mãe Vera de } \\
\text { lansã }\end{array}$ & 2 & Mãe leda de Ogum & 3 \\
\hline $\begin{array}{l}\text { Pai Augusto } \\
\text { de Oxalá }\end{array}$ & 2 & Mãe Taís de Xapanã & 3 \\
\hline $\begin{array}{l}\text { Pai Beto de } \\
\text { Oxalá }\end{array}$ & 2 & Pai Marcos de Xangô & 3 \\
\hline $\begin{array}{l}\text { Pai Clóvis de } \\
\text { Xangô }\end{array}$ & 2 & Pai Ricardo de Oxum & 4 \\
\hline $\begin{array}{l}\text { Pai Dejair de } \\
\text { Ogum }\end{array}$ & 2 & Mãe Fernanda de Xapanã & 4 \\
\hline $\begin{array}{l}\text { Pai Gabriel de } \\
\text { Xangô }\end{array}$ & 2 & Pai Mozart de lemanjá & 6 \\
\hline $\begin{array}{l}\text { Pai Maninho } \\
\text { de Ogum }\end{array}$ & 2 & Pai Cleon de Oxalá & 8 \\
\hline $\begin{array}{l}\text { Pai Paulinho } \\
\text { de Odé }\end{array}$ & 2 & Pai Chiquinho de Oxalá & \\
\hline $\begin{array}{l}\text { Pai Paulinho } \\
\text { Do Xoroquê }\end{array}$ & 2 & & \\
\hline
\end{tabular}


Esses dados preliminares podem ser expandidos a fim de perceber outras variáveis passíveis de análise, tais como gênero, idade presumível, cor, local da entrevista, etc. Mas a proposta deste trabalho se atém em uma postagem específica da página Kizomba. ${ }^{8}$

A página foi criada no ano de 2016, e desde o início é apresentada pelo jornalista Israel Ávila (nome religioso Israel de Xangô Aganjú), que antes desse projeto esteve envolvido com iniciativas voltadas para a divulgação do carnaval de Porto Alegre. Natural de Sapiranga, e filho de pai Babalorixá, mesmo sendo pronto, tem se dedicado a divulgação através das redes sociais (além do Facebook o Kizomba está no Instagram e no Youtube) da cultura afro-gaúcha através de entrevistas com afrorreligiosos, cobertura (fotos e vídeos) de festas públicas e divulgação de produtos relativos a esse universo. Em entrevista em comemoração do primeiro ano do programa, ${ }^{9}$ Israel explica a motivação para a criação do Kizomba:

Porque o povo de matriz africana tem poucas janelas, pra gritar, pra falar suas histórias. A gente tem muitas janelas fotográficas, tinha algumas janelas de áudio. O próprio celular com vídeo facilitou para que a gente pudesse mostrar algumas coisas, mas faltava alguma coisa da pessoa procurar, garimpar as histórias. E isso a gente começou a fazer, e graças aos orixás deu tudo certo.

Os vídeos disponibilizados na página geralmente são entrevistas nas quais o convidado rememora sua trajetória religiosa e traz suas impressões sobre a religião no momento presente. Contudo, um vídeo ${ }^{10}$ postado em 05/08/2019 faz uma homenagem ao Exu Reio das Sete Encruzilhadas (entidade de Mãe leda de Ogum, Porto Alegre), que em alguns dias completaria 59 anos de chegada.

\footnotetext{
8 Segundo explicação do próprio dono da página, significa festa do povo.

${ }^{9}$ As informações foram obtidas em entrevista. Disponível em: https://www.youtube.com/watch?v=JcXDloeiFeU. Acesso em: 31 out.2020.

10 Disponível em: https://www.facebook.com//kizombaTV/posts/2176459842463313. Acesso em 22 out.2020.
} 
Figura 1 - Print do início do vídeo em homenagem à Seu Sete de Mãe leda de Ogum.

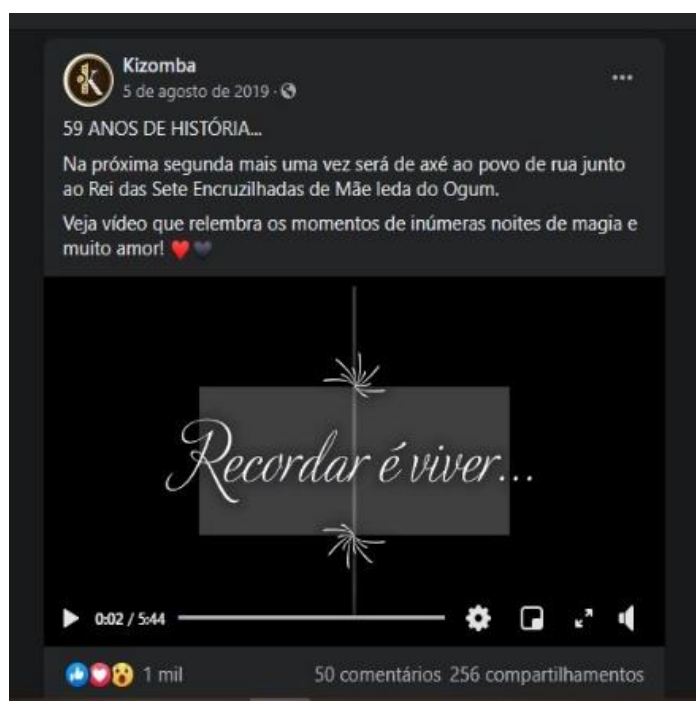

Fonte: Kizomba

No vídeo de $5 \min 44 \mathrm{~s}$, com um ponto antigo de exu como trilha musical, 112 fotografias ${ }^{11}$ da Yalorixá incorporada com sua entidade vão se sucedendo.

Para além da contemplação de cunho religioso feita por partícipes afrogaúchos, ou uma observação curiosa sobre fotografias que para leigos possam se apresentar como "exóticas", uma "única imagem contém em si um inventário de informações acerca de um determinado momento passado; ela sintetiza no documento um fragmento do real visível, destacando-o do contínuo da vida" (KOSSOY, 2001, p. 101), trata-se de uma oportunidade de análise da passagem do tempo da entidade quando na médium, ou das mudanças tecnológicas das fotos em si.

\footnotetext{
"A maior parte das fotografias fazem parte do acervo pessoal da Yalorixá.
} 
Figura 2 -Print de vídeo de fotos de Mãe leda incorporada com Seu Sete.

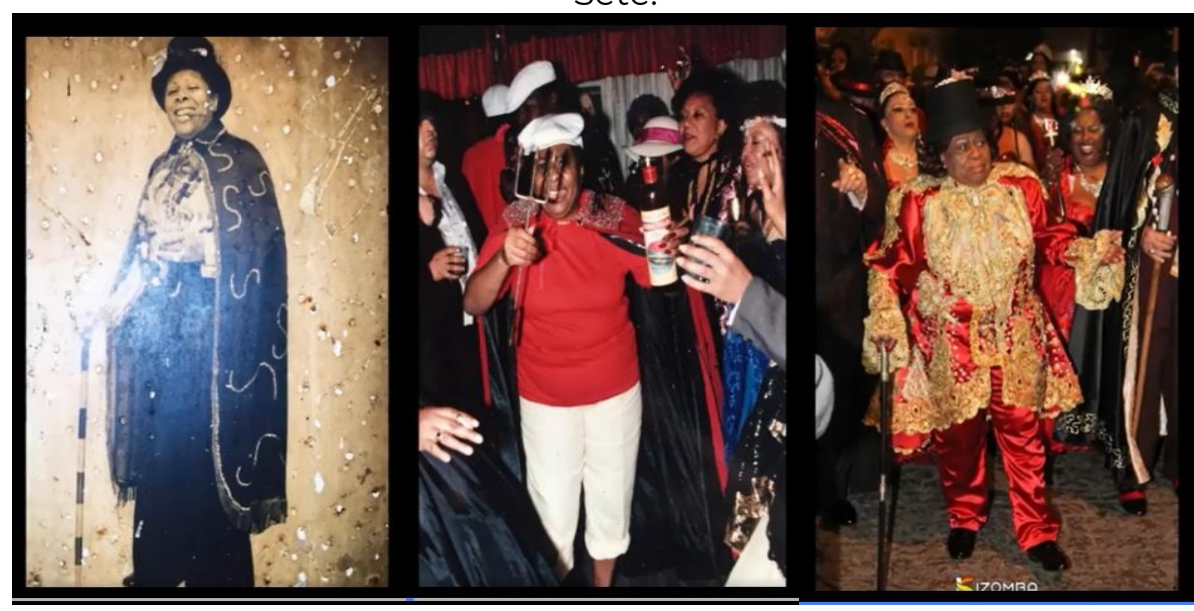

Fonte: Kizomba

É obvio que a representação fotográfica reflete e documenta em seu conteúdo não apenas uma estética inerente à sua expressão mas também uma estética de vida ideologicamente preponderante num particular contexto social e geográfico, num momento preciso da história (KOSSOY, 2001, p. 133).

As fotografias das religiões de matriz africana contêm uma série de símbolos, seja nos trajes, na decoração, na fartura alimentar, e estes representam uma estética diretamente relacionada às sociabilidades intrínsecas à essas culturas religiosas, e nas festas essas categorias podem ser melhor analisadas por serem momentos públicos e mais facilmente fotografados.

Figura 3 -Print de vídeo de fotos de Seu Sete interagindo com convidados.

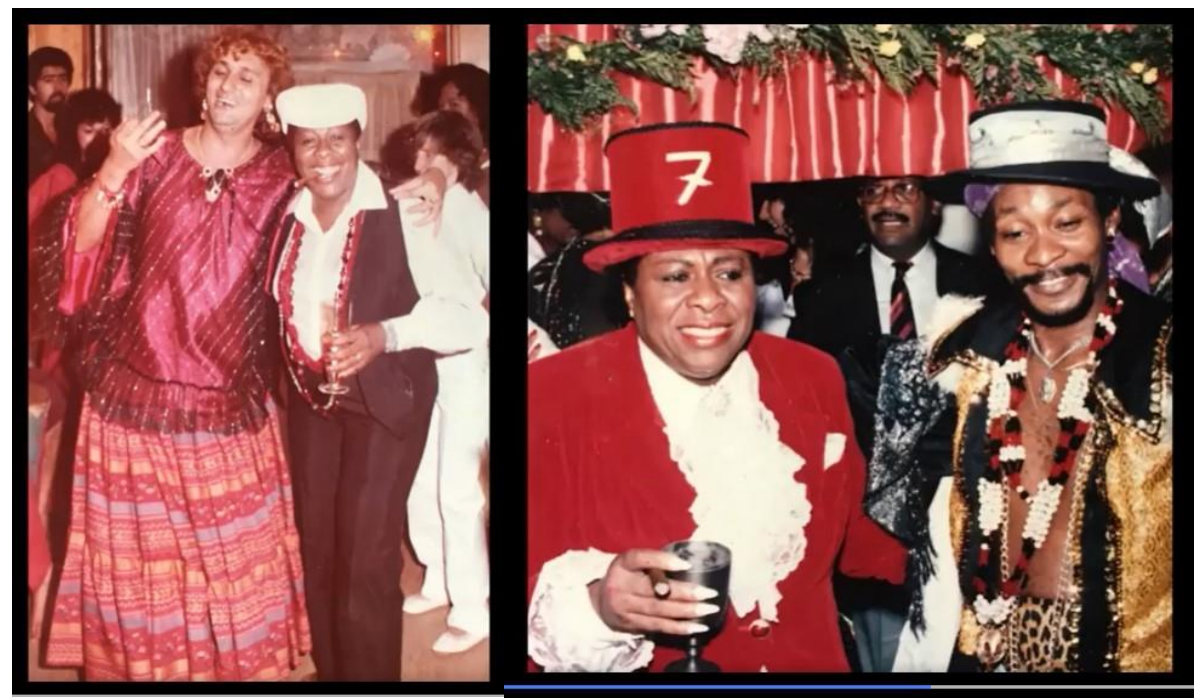

Fonte: Kizomba. 
Como fonte de informação, as fotografias encontradas em páginas das redes sociais permitem conhecer como estas culturas se autorrepresentam, como ocupam os espaços virtuais, sua inserção na sociedade envolvente, como experienciam seus ritos e crenças quando nas festas públicas, quais seus gostos, trajetos e histórias. Contudo, as emoções (positivas e/ou negativas) que estas imagens despertam não podem ser analisadas somente pelas curtidas. As mensagens deixadas pelos usuários são mais uma ferramenta de análise que auxilia o pesquisador a perceber se lembranças foram despertadas, se houve atualizações ou modificações nos rituais, se há "reencontros" com pessoas ou momentos passados.

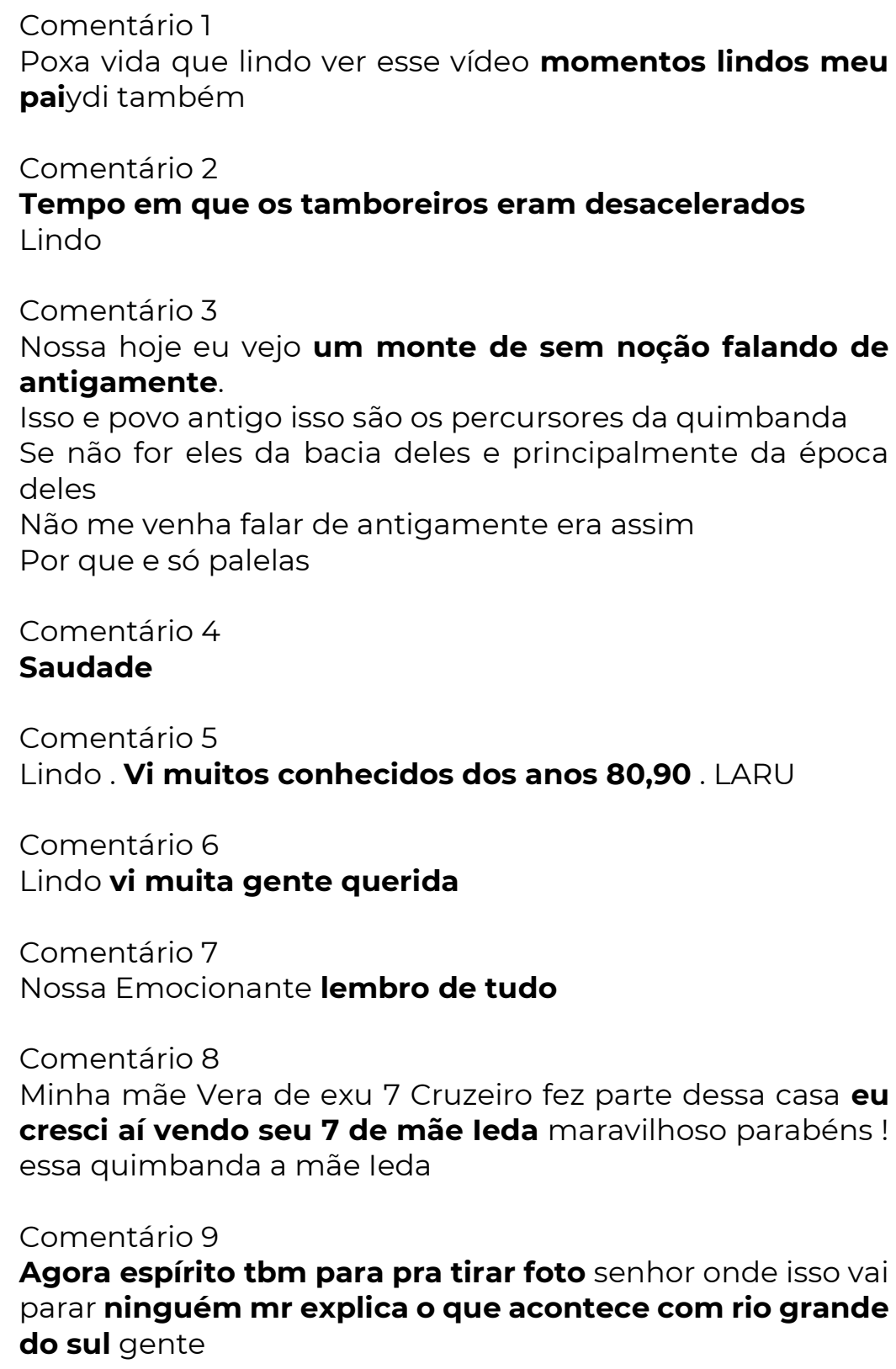
parar ninguém $\mathrm{mr}$ explica o que acontece com rio grande do sul gente 


\section{Réplica 1}

Will Lande se você prestar atenção e não somente olhar com o olhar de criticar, verá que este Exu tem uma longa caminhada aqui na terra. São 59 anos que este espírito chega nesta senhora. Talvez vc não fosse nem nascido. Olha bem antes de criticar e verás que as fotos são bem antigas. Quer dizer que sempre se bateu fotos de Exu. Eu tbm gostaria o que acontece com as pessoas que adoram criticar sem conhecimento de causa.

Tréplica 1

Juçara Silva jussara conheço bem sim estou criticando pq sei q isso nao existe viro em espirito que tem ate mais q 59 anos vem em terra. E o mesmo sra juçara lhe digo isso nao existe não espirito pousando pra foto... esta errado sim e nao defendo nao... uma vez determinado cliente foi tirar foto de meu exu. A maquina ou celular nao lembro bem simplesmente queimo e nao havia nada la.... desculpa meu anjo sei do que digo sem duvida... minha zeladora roda a 65 anos no exu dela e tbmn ao faz esta palhacada. Sem mais MAKUIU KANDANDO KAMBA

\section{Comentário 10}

Carla Taís olha a mãe aparece em algumas fotos

\section{Comentário 11}

Lindo mesmo rever grandes amigos salve o povo. [grifos nossos] $]^{12}$

Assim, as redes sociais se constituem em um espaço público, não por se opor ao privado, mas por se aproximar do "que é comum a um grupo, a uma classe, a um gênero, etc." (MAUAD, 2018, p. 256). E no caso das religiões de matriz africana, os laços existentes entre os religiosos desse grupo são multiplexos, "constituídos de diversos tipos de relações sociais (RECUERO, 2009, p. 42), ou seja, ocorrem não somente em outras plataformas, como o Youtube e o Instagram, mas também fora do ambiente virtual, principalmente em eventos como as festas públicas. Novamente temos a aproximação dessas culturas religiosas com as redes sociais, pois estas são ambientes permeados de hibridismos.

E o interessante é que esta plataforma, por apresentar uma justaposição de espaços online, permite uma série de formas síncronas e assíncronas de interação em um mesmo espaço, que são o recurso de comentário (espaço para minifóruns de discussão); upload de fotos (informação não verbal), figuras e vídeos; e conexões intertextuais entre textos e recursos disponíveis online pela função 'curtir' [...]. Isso estabeleceu uma nova forma de linguagem, no qual o discurso (ex.:

\footnotetext{
12 Foram selecionados comentários com alguma argumentação, sendo que optou-se por substituir os nomes dos usuários e deixar suas falas completas.
} 
'comentário de Facebook') [...] passou a ser espaços públicos comunicativos com características híbridas, ou seja, espaços com interações cada vez mais públicas que ocorrem tanto na forma verbal quanto não verbal (RESENDE, 2020, p. 231).

$\mathrm{E}$, se as religiões de matriz africana chegaram até o presente - mesmo sendo perseguidas ao longo das décadas, seja pelo Estado, pela imprensa ou por uma religião dominante -, é porque uma das estratégias (por conveniência ou necessidade) utilizadas pelos primeiros afrorreligiosos foi o hibridismo, a mistura com as sociedades, culturas, costumes, alimentos, geografias locais. Trata-se de um processo de atualização constante, agora impulsionado por novas tecnologias que alçam a tradição a um novo "espaço".

\section{Considerações finais}

Ao longo deste artigo procurou-se refletir sobre as relações entre as redes sociais, a memória e a história das religiões de matriz africana. Considerando que as tecnologias, como a fotografia, sempre estiveram presentes nos terreiros, por serem tradicionais não se pode entender que se tratem de culturas religiosas estagnadas no tempo.

Dinâmicas por natureza, tendo em vista como se deu sua formação no território brasileiro, atualizam-se conforme a sociedade envolvente vai se adaptando às novas tecnologias. Todavia, certos capitais sociais presentes nas religiões afro-brasileiras, tal como visibilidade, reputação, popularidade, autoridade, cooperação, competição e conflito, também são elementos que constituem as redes sociais, viabilizando um engajamento ao Facebook em que certos usos e costumes dos religiosos seguem em seu conteúdo, adaptando-se somente ao formato.

Desse modo a migração das fotografias físicas para o universo on-line não causa o mesmo impacto que ocorre com os álbuns familiares, tendo em vista que os registros imagéticos nas culturas afrorreligiosas são feitos sobre as festas públicas, de modo que o que é eternizado são momentos com outros religiosos (família religiosa, visitas de outros donos de terreiros, etc.). Mesmo assim, as redes como o Facebook propiciam o arquivamento de dados pertinentes à história das religiões de matriz africana. 
Como estudo de caso é analisado um vídeo postado pela página Kizomba que, para homenagear os 59 anos de chegada do exu de Mãe leda de Ogum, Seu Sete, faz uma montagem com várias fotos do acervo pessoal da religiosa. Somente a observação dessas imagens já possibilitaria fazer uma pesquisa referente à história das religiões afro-gaúchas a partir de várias categorias como vestimenta, sociabilidades, técnica fotográfica, ritos, etc. Todavia, pode-se somar a essa fonte a análise dos comentários dessa postagem, em que alguns apontam o despertar de lembranças e saudades seja de ter estado naquelas festividades ou das pessoas que reconheceram, outros apontam para a mudança das práticas, enquanto outros - de outros estados - estranham certos comportamentos das entidades. O Facebook, assim como outras redes sociais, é um grande arquivo de possibilidades para o entendimento de mudanças que ocorrem na sociedade, basta escolher bem as palavras-chaves que serão digitadas no "campo de pesquisa".

\section{Referências}

BELEZA, J.; MÜLLER, J.; PEREIRA, C. da S. Museus, coisas e pessoas: três estudos de caso para refletir sobre os vínculos entre materialidade e vida social. Anais do Museu Paulista, v. 27, pp. 1-24, 2019.

CANABARRO, I. Fotografia e História: questões teóricas e metodológicas. Visualidades, Goiânia v. 13, n. 1, pp. 98-125, jan./jun., 2015.

CANDAU, J. Antropologia da memória. Trad. Miriam Lopes. Lisboa: Instituto Piaget, 2005. 2018.

Memória e identidade. Trad. Maria Letícia Pereira. São Paulo: Contexto,

CATROGA, F. Memória e História. In: PESAVENTO, S. J. (org.). Fronteiras do milênio. Porto Alegre: Ed. Universidade UFRGS, 2001, pp. 43-69.

CASTILLO, L. E. A fotografia e seus usos no Candomblé da Bahia. Pontos de Interrogação, v. 3, n. 2, pp. 41-71, jul./dez., 2013.

CORREAA, N. F. Sob o signo da ameaça: conflito, poder e feitiço nas religiões afro-brasileiras. Tese (Doutorado em Antropologia) - Programa de Estudos Pós-Graduados em Ciências Sociais, Pontifícia Universidade Católica de São Paulo, São Paulo, 1998.

CUNHA, M. R. da. A Memória na era da reconexão e do esquecimento. Em Questão, Porto Alegre, v. 17, n. 2, pp. 103-117, jul./dez. 2011.

KOSSOY, B. História e Fotografia. São Paulo: Ateliê Editorial, 2001. 
MAUAD, A. M. Imagens em fuga: considerações sobre espaço público visual no tempo presente. Revista Tempo e Argumento, Florianópolis, v. 10, n. 23, pp. 252 - 285, jan./mar.2018.

MUSSE, M. F. Do álbum de família ao álbum afetivo: as narrativas da memória que transitamentre a fotografia analógica e a digital. Lumina, v. 13, n. 1, pp. 7790, abr. 2019.

PRANDI, R. As religiões negras do Brasil - Para uma sociologia dos cultos afrobrasileiros. Revista USP, n. 28, pp. 64-83, mar. 1996.

PREVITALLI, I. M.; ALVES, S. Fotografia: ver e ser visto no Candomblé. Ponto-eVírgula, v. 2, pp. 68-80, 2007.

RAMOS, C. P. C. O Discurso da Luz (Imagens das Religiões AfroBrasileiras no Arquivo do Jornal A Tarde). Dissertação (Mestrado em Estudos Étnicos e Africanos) - Faculdade de Filosofia e Ciências Humanas, Universidade Federal da Bahia (UFBA), 2009.

RECUERO, R. Redes sociais na internet. Porto Alegre: Sulina, 2009.

RENDEIRO, M. E. L. S.; RIBEIRO, L. B. Narrativas no ciberespaço - memória, informação e imagem no universo das redes sociais. In: XIII Encontro Nacional de Pesquisa em Ciência da Informação - ENANCIB, UNIRIO, 2012.

RENDEIRO, M. E. S. Orkut e Facebook: as teias da memória em meio às redes sociais. Ciências Sociais Unisinos, v. 47, n. 3, p. 256-262, set./dez.2011.

RESENDE, D. C. P.; POLETTO, R. de S; BARROS, E. M. D. de. A modelização do gênero "comentário argumentativo do Facebook". Raído, Dourados, MS, v. 14, n. 34, pp. 225-243, jan./abr. 2020.

SONTAG, S. Ensaios sobre a fotografia. Trad. Rubens Figueiredo. São Paulo: Companhia das Letras, 2004. 